\title{
The recurrence rate of venous thromboembolism after a first or second episode of deep venous thrombosis was high
}

Hansson PO, Sörbo J, Eriksson H. Recurrent venous thromboembolism after deep vein thrombosis. Incidence and risk factors. Arch Intern Med 2000 Mar 27;160:769-74.

QUESTIONS: For patients who had a first or second episode of confirmed arm or leg deep venous thrombosis (DVT), what is the incidence of recurrent venous thromboembolism (VTE) (DVT or pulmonary embolism [PE]), and what are the risk factors for recurrence?

Design

Cohort study with 3.7 to 8.8 years of follow up.

Setting

A university hospital in Göteborg, Sweden.

\section{Patients}

738 patients with DVT confirmed by phlebography or color duplex ultrasonography who had been discharged from the hospital and survived to 1 month. 591 patients (mean age $66 \mathrm{y}, 53 \%$ women) had a first DVT, and 147 patients had previous VTEs (108 patients with a previous DVT, 19 with a previous PE, and 20 with both DVT and PE). Follow up for mortality was $>99 \%$.

\section{Assessment of prognostic factors}

Data on prognostic factors were collected and used in multivariate analyses: age, sex, duration of oral anticoagulant treatment, location of DVT (arm or leg), level of DVT in leg (distal or proximal), initial antithrombotic treatment, history of VTE, surgery within the past 3 months, immobilisation within 1 week of index DVT, and cancer.

\section{Main outcome measures}

Recurrent fatal and non-fatal VTE.

\section{Main results}

During follow up, of the 591 patients in the group who had had a first DVT, 109 (18\%) had a recurrent VTE (84 DVTs, 14 non-fatal PEs, and 13 fatal PEs). The mortality rate was $42 \%$ overall. Of the 136 patients who had had 1 previous VTE, 37 (27\%) had a recurrent VTE (26 DVTs, 9 non-fatal PEs, and 2 fatal PEs). The table shows cumulative incidences for both groups. Multivariate analysis showed that 3 factors increased the risk for recurrent VTE: proximal DVT as an index event (relative risk [RR] $2.30,95 \%$ CI 1.55 to 3.42 ); cancer (RR 2.21, CI 1.43 to 3.41 ); and history of VTE (RR 1.71 , CI 1.16 to 2.52 ).

Cumulative incidence of recurrence of venous thromboembolism after a first or second episode of deep venous thrombosis (DVT)

\section{Time}

period After first DVT (95\% Cl) After second DVT (Cl)

Tr $P$ O Hespondence:

Dr P O Hansson

Medicine, Sahlgrenska

University.

Hospital-Östra,

SE-41685 Göteborg,

Sweden. Fax +4631

3388694.

\begin{tabular}{lll} 
1 year & $7.0 \%(4.8$ to 9.1$)$ & $7.6 \%(3.1$ to 12$)$ \\
\hline 2 year & $12 \%(9.3$ to 15$)$ & $16 \%(9.3$ to 22$)$ \\
\hline 3 year & $15 \%(12$ to 18$)$ & $19 \%(12$ to 26$)$ \\
\hline 4 year & $18 \%(14$ to 21$)$ & $26 \%(18$ to 34$)$ \\
\hline 5 year & $22 \%(18$ to 25$)$ & $28 \%(20$ to 36$)$ \\
\hline
\end{tabular}

2 factors decreased the risk for recurrent VTE: DVT after surgery (RR 0.27 , CI 0.13 to 0.55 ) and long term anticoagulant treatment (RR 0.95 , CI 0.92 to 0.98 ).

\section{Conclusions}

The recurrence rate of venous thromboembolism was high. The risk for recurrence was increased if the index event was a proximal deep venous thrombosis, if the patient had a history of venous thromboembolism or cancer but not recent surgery, or if the duration of the initial anticoagulant treatment period had been short.

\section{COMMENTARY}

Hansson et al have shown that rates of recurrent VTE remain high despite the standard clinical practice of 3 months of prophylactic oral anticoagulation. Kearon et al eloquently showed that after an initial episode of idiopathic VTE the rate of recurrence was $27.4 \%$ /patient year with placebo and $1.3 \%$ patient year with continued warfarin. Schulman et al found that prophylactic oral anticoagulation after initial VTE for 6 months rather than 6 weeks reduced recurrence rates. ${ }^{2}$ Furthermore, long term prophylaxis after a second VTE resulted in lower recurrence rates than did 6 months of prophylaxis, although with more major bleeding. ${ }^{3}$

These studies provide compelling evidence that VTE should be viewed as a "chronic polygenic disorder," with acute exacerbations and that extended prophylactic anticoagulation in patients with idiopathic VTE and VTE associated with persistent risk factors for thrombosis needs to be strongly considered. Hansson et al did not present data on the presence of factor $\mathrm{V}$ Leiden, 1 of the most common inherited hypercoagulable states associated with recurrent VTE. ${ }^{5}$ It is unclear whether long term prophylaxis in patients with factor V Leiden who have an initial VTE is warranted, considering that the risk for anticoagulant related bleeding is directly associated with the duration of treatment. ${ }^{6}$ The results of an ongoing trial to assess the efficacy of extended low dose warfarin in the secondary prevention of VTE among patients with and without factor V Leiden will, I hope, provide much needed answers.

Rebecca J Beyth, MD, MS Baylor College of Medicine Houston, Texas, USA

1 Kearon C, Gent M, Hirsh J, et al. N Engl J Med 1999;340:901-7.

2 Schulman S, Rhedin AS, Lindmarker P, et al. $N$ Engl J Med 1995;332:1661-5.

3 Schulman S, Granqvist S, Holmstrom M, et al. N Engl J Med 1997;336:393-8.

4 Schafer AI. N Engl J Med 1999;340:955-6.

5 Simioni P, Prandoni P, Lensing AW, et al. N Engl J Med 1997; 336:399-403.

6 Levine MN, Raskob G, Landefeld S, et al. Chest 1998; 114:511S-23S

7 Ridker PM. Vasc Med 1998;3:67-73. 